\title{
活性炭素䄉維紙捕集/ガスクロマトグラフィーによる大気中の 殺菌剤キャプタン及びクロロタロニルの簡易分析方法
}

\author{
川田 邦明 ${ }^{\circledR}$, 森 山 登, 漆山 佳雄*
}

(1990 年 5 月 7 日受理)

\section{1 緒言}

代表的な殺菌剂キャプタン $\{N$-(trichloromethylthio)cyclohex-4-ene-1,2-dicarboximide; captan\} 及 び TPN (tetrachloroisophthalonitrile; chlorothalonil) は, 稲, 果樹, 野菜生産のみでなく"), ゴルフ場の芝生 管理にも使用されており，特に呼吸による人体影響が懸 念されている. しかし, 両殺菌剤の空気中濃度の測定例 は少な(2) 5). 分析方法として, キャプタンをポリウ レタンフォーム ${ }^{2)}$, XAD-4 樹脂又は XE-340 樹脂5) で, 又, TPNをポリウレタンフォーム年3)や Tenax GC 樹脂4)で, 各々捕集後, GC で定量する方法があるが, いずれも取り扱いの煩雑さや回収率の点で問題があり, 簡便な方法の開発が望まれていた。

著者らは，大気中又は地表に落下した殺虫剤を活性炭 素繊維紙で捕集後, GC で測定する方法を開発し $た^{6) 7)}$. そこで, 大気中のキャプタン及び TPNを自動 大気採取装置を使用し, 活性炭素瀻維紙で捕集後, GC で測定する方法を検討したところ，良好な結果を得たの で報告する.

\section{2 実験}

\section{$2 \cdot 1$ 装置及び試薬}

自動大気採取装置は東京ダイレック製 10 ライング ローバルサンプラー GS-10D を用いた. GC 装置は島 津製作所製 GC-9A（ECD, 電子捕獲型検出器付き) を, カラムは Hewlett Packard 製シリーズ $530 \mu$ カラム HP-1 (メチルシリコンを厚さ $2.65 \mu \mathrm{m}$ で被覆した長さ $10 \mathrm{~m}$, 内径 $0.53 \mathrm{~mm}$ の溶融シリカキャピラリーカラ ム）を用いた。その他の装置は既報のものを用い $た^{6 / 7)}$.

* 新潟県衛生公害研究所: 950-21 新潟県新潟市兽和 314-1
殺菌剤標準品は和光純薬工業製標準品を使用した。キ シレンは和光純薬工業製特級試薬を全ガラス製蒸留装置 で蒸留して使用した。トルエン及びエチルベンゼンは和 光純薬工業製特級試薬を, その他の溶媒は和光純薬工業 製残留農薬試験用を使用した。

捕集沪紙は，既報昼と同様に值径 $47 \mathrm{~mm}$ に切り抜いた 活性炭素纎維紙（東洋紡績製 $\mathrm{KF}$ ペーパーP-175） に,キシレンを加え, 15 分間超音波を照射後, 別のキ

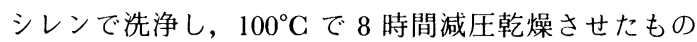
を用いた。

\section{$2 \cdot 2$ 捕集及び定量方法}

捕集沪紙を 2 枚重ねて自動大気採取装置にセット し, 10〜201 min-1 で 3 時間大気を吸引する. 回収し た捕集沪紙は各々別に細片とし，10 ml 共栓付き遠沈管 に入れ，キシレン $3 \mathrm{ml}$ を加え，10 分間超音波抽出後, $3000 \mathrm{rpm}$ で 10 分間遠心分離し, 上澄みの一部を GC に直接注入法で注入し, ピーク高さから絶対検量線法に より試料中のキャプタン及び TPN 濃度を定量する. $\mathrm{GC}$ 条件を以下に示す. カラム温度 : $240^{\circ} \mathrm{C}$; 注入口及び 検出器温度: $270^{\circ} \mathrm{C}$; キャリヤーガス: 窒素 $5 \mathrm{ml} \mathrm{min}^{-1}$; 検出器: $\operatorname{ECD}\left({ }^{63} \mathrm{Ni}\right)$.

\section{3 結果と考察}

\section{$3 \cdot 1$ 分析方法の検討}

捕集洰紙に既知量のキャプタン及び TPN をベンゼン 溶液として添加後, 風乾したものを用いて, 種々の溶媒 の抽出率を求めた. その結果, Table 1 に示すように, 著者らが既報6)7)で殺虫剤の抽出に使用したベンゼンーエ 夕ノール $(4: 1 \mathrm{v} / \mathrm{v})$ では, TPN が十分回収されなか ったが，キシレンを用いれば両殺菌剤とも良好に抽出で きることが分かった。

次に，捕集沪紙に $2 \mu \mathrm{g}$ のキャプタン及び TPNをべ 
Table 1 Extraction efficiencies for fungicides from an activated carbon fiber paper

\begin{tabular}{|c|c|c|c|}
\hline \multirow{2}{*}{$\begin{array}{l}\text { Extraction } \\
\text { solvent }\end{array}$} & \multicolumn{2}{|c|}{$\begin{array}{l}\text { Extraction } \\
\text { efficiency, \% }\end{array}$} & \multirow{2}{*}{$\begin{array}{c}\text { Added } \\
\mu \mathrm{g}\end{array}$} \\
\hline & Captan & TPN & \\
\hline Benzene-ethanol $^{\text {a) }}$ & 92 & 51 & 2.0 \\
\hline Ethanol & 47 & 0.7 & 2.0 \\
\hline Benzene & 86 & 40 & 2.0 \\
\hline Hexane & 1.8 & 0.8 & 2.0 \\
\hline Acetone & 92 & 3.4 & 2.0 \\
\hline Ethyl ether & 21 & 0.5 & 2.0 \\
\hline Ethyl acetate & 87 & 3.6 & 2.0 \\
\hline Acetonitrile & 104 & 18 & 2.0 \\
\hline Dichloromethane & 92 & 21 & 2.0 \\
\hline Ethylbenzene & 89 & 48 & 2.0 \\
\hline \multirow[t]{2}{*}{ Toluene } & $90 \pm 3.7^{\mathrm{b})}$ & $89 \pm 2.4^{\mathrm{b})}$ & 2.0 \\
\hline & $98 \pm 5.7^{b)}$ & $74 \pm 6.4^{\mathrm{b})}$ & 0.2 \\
\hline Toluene-ethanol $^{\text {a) }}$ & 84 & 79 & 2.0 \\
\hline \multirow[t]{2}{*}{ Xylene } & $97 \pm 1.5^{\mathrm{b})}$ & $97 \pm 1.7^{\mathrm{b})}$ & 2.0 \\
\hline & $96 \pm 5.6^{\mathrm{b})}$ & $90 \pm 3.6^{\mathrm{b})}$ & 0.2 \\
\hline
\end{tabular}

a) $4: 1 \mathrm{v} / \mathrm{v}$; b) mean \pm standard deviation $(n=5)$

Table 2 Recoveries of fungicides from the activated carbon fiber papers

\begin{tabular}{|c|c|c|c|}
\hline \multirow{2}{*}{ Fungicide } & \multicolumn{2}{|c|}{ Recovery $^{\text {a) }}, \%$} & \multirow{2}{*}{$\begin{array}{l}\text { Flow rate/ } \\
1 \mathrm{~min}^{-1}\end{array}$} \\
\hline & Front & Front + back & \\
\hline \multirow[t]{2}{*}{ Captan } & $93 \pm 4.9$ & $94 \pm 4.3$ & 10 \\
\hline & $93 \pm 4.3$ & $94 \pm 2.8$ & 20 \\
\hline \multirow[t]{2}{*}{ TPN } & $93 \pm 3.2$ & $97 \pm 1.9$ & 10 \\
\hline & $93 \pm 2.3$ & $95 \pm 4.4$ & 20 \\
\hline
\end{tabular}

a) mean \pm standard deviation $(n=5)$

ンゼン溶液として添加し, 風乾後, 殺菌剤を添加してい ない別の捕集沃紙を下流側に重ねて 2 段とし，3 時間吸 引した場合の 2 枚の捕集沪紙からの殺菌剂の回収率を Table 2 に示す. 吸引流量が $10 \sim 201 \mathrm{~min}^{-1}$ で両殺菌 剤とも良好な回収結果が得られた。そこで, 実際の捕集 では捕集沪紙を 2 枚重ねて捕集することとし，2 枚の捕 集沪紙を別々に分析し, 捕集率を確認することとした。 なお，キャプタン及び TPN はいずれも $\mathrm{GC} て ゙ ~ 0.004 \mathrm{ng}$ まで定量可能であったことから, 抽出液の $1 \mu \mathrm{l}$ を GC に注入した場合, 定量下限值は $4 \mathrm{ng} \mathrm{m}^{-3}$ であった。

更に，一定量のキャプタン及び TPN を添加した捕集 洰紙を $-20^{\circ} \mathrm{C}$ で保存した場合の安定性を検討した。 の結果, Table 3 に示すように 1 週間の保存が可能なこ とが分かった.
Table 3 Stabilities of fungicides on the activated carbon fiber paper

\begin{tabular}{|c|c|c|c|c|}
\hline \multirow{2}{*}{$\begin{array}{c}\text { Added/ } \\
\mu \mathrm{g}\end{array}$} & \multirow{2}{*}{$\begin{array}{l}\text { Storage } \\
\text { time/d }\end{array}$} & \multicolumn{2}{|c|}{ Recovery $^{\text {a) }}, \%$} & \multirow{2}{*}{$n$} \\
\hline & & Captan & TPN & \\
\hline 0.2 & 0 & $96 \pm 5.6$ & $90 \pm 3.6$ & 2 \\
\hline 2.0 & 0 & $97 \pm 1.5$ & $97 \pm 1.7$ & 2 \\
\hline 2.0 & 2 & $90 \pm 2.1$ & $98 \pm 1.1$ & 2 \\
\hline 0.2 & 7 & $96 \pm 3.6$ & $92 \pm 7.0$ & 3 \\
\hline 2.0 & 7 & $90 \pm 3.2$ & $94 \pm 4.9$ & 3 \\
\hline
\end{tabular}

a) mean \pm standard deviation

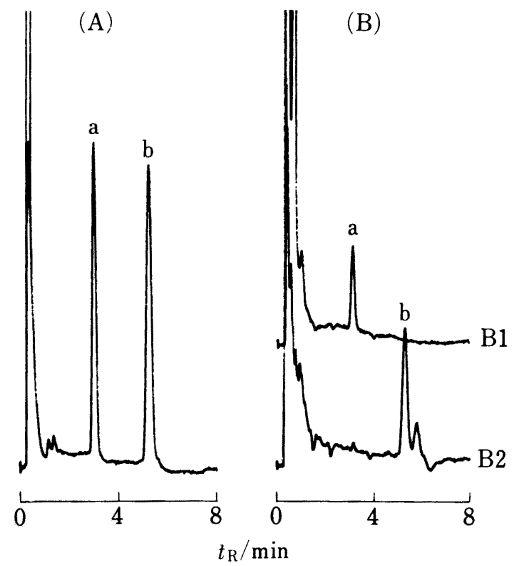

Fig. 1 Typical gas chromatograms of fungicides

(A) standard; (B) two samples (B1 and B2): a : chlorothalonil; b: captan. Operating conditions for GC-Column : fused silica capillary column coated with methyl silicone $\left(d_{\mathrm{f}}=2.65 \mu \mathrm{m}, 0.53 \mathrm{~mm}\right.$ i.d. $\left.\times 10 \mathrm{~m}\right)$; Column temperature : $240^{\circ} \mathrm{C}$; Injection and detector temperature: $270^{\circ} \mathrm{C}$; Carrier gas : $\mathrm{N}_{2}, \quad 5 \mathrm{ml}$ $\min ^{-1}$; Detector : ECD $\left({ }^{63} \mathrm{Ni}\right)$

\section{$3 \cdot 2$ 実環境への応用}

本法を用いてキャプタン及び TPN が散布されたゴル フ場周辺で調査した。測定例を Table 4 に示す。一部 の試料から, 散布された殺菌剂が $4 \sim 40 \mathrm{ng} \mathrm{m}^{-3}$ と微量 ながら検出された。使用した 2 枚の洰紙の両方から殺 菌郕が検出された例について，捕集率を $\left\{\left(A_{\text {front }}-A_{\text {back }}\right) / A_{\text {front }}\right\} \times 100$ により算出し, Table 4 に あわせて示す。ただし， $A_{\text {front }}$ 及び $A_{\text {back }}$ は，それぞ れ，前段及び後段の捕集沪紙に捕集された殺菌剤の量で ある。その結果，捕集率はいずれも $95 \%$ 以上と良好で あった。ガスクロマトグラム例を Fig. 1 に示す。いず れの試料とも，特に妨害もなく定量可能であった。 
Table 4 Analytical results for fungicides in air near golf courses

\begin{tabular}{|c|c|c|c|c|c|c|c|c|c|c|}
\hline \multicolumn{2}{|c|}{ Sample site } & \multirow{3}{*}{ Date } & \multicolumn{4}{|c|}{ Amount/ng } & \multirow{2}{*}{\multicolumn{2}{|c|}{$\begin{array}{l}\text { Concentra- } \\
\text { tion/ng m }{ }^{-3}\end{array}$}} & \multirow{2}{*}{\multicolumn{2}{|c|}{$\begin{array}{l}\text { Collection } \\
\text { efficiency }{ }^{c)}, \%\end{array}$}} \\
\hline \multirow{2}{*}{$\begin{array}{l}\text { Golf } \\
\text { course }\end{array}$} & \multirow[b]{2}{*}{ Site } & & \multicolumn{2}{|c|}{$A_{\text {front }}{ }^{\text {a) }}$} & \multicolumn{2}{|c|}{$A_{\text {back }}{ }^{\mathrm{b})}$} & & & & \\
\hline & & & Captan & TPN & Captan & TPN & Captan & TPN & Captan & TPN \\
\hline \multirow[t]{8}{*}{ A } & \multirow[t]{8}{*}{1} & \multirow{8}{*}{$\begin{array}{l}\text { Aug. } 18 \\
\sim 19 \\
1989\end{array}$} & $<14$ & $<14$ & $<1.4$ & $<1.4$ & $<4$ & $<4$ & - & - \\
\hline & & & 36 & $<14$ & 1.4 & $<1.4$ & 10 & $<4$ & 96 & - \\
\hline & & & $<14$ & $<14$ & $<1.4$ & $<1.4$ & $<4$ & $<4$ & - & - \\
\hline & & & $<14$ & $<14$ & $<1.4$ & $<1.4$ & $<4$ & $<4$ & - & - \\
\hline & & & $<14$ & $<14$ & $<1.4$ & $<1.4$ & $<4$ & $<4$ & - & - \\
\hline & & & $<14$ & $<14$ & $<1.4$ & $<1.4$ & $<4$ & $<4$ & - & - \\
\hline & & & 22 & $<14$ & $<1.4$ & $<1.4$ & 6 & $<4$ & - & - \\
\hline & & & 25 & $<14$ & $<1.4$ & $<1.4$ & 7 & $<4$ & - & - \\
\hline \multirow[t]{8}{*}{ B } & \multirow[t]{8}{*}{1} & Sep. 4 & $<14$ & 40 & $<1.4$ & $<1.4$ & $<4$ & 11 & - & - \\
\hline & & $\sim 5$ & $<14$ & 44 & $<1.4$ & 2.2 & $<4$ & 13 & - & 95 \\
\hline & & 1989 & $<14$ & 15 & $<1.4$ & $<1.4$ & $<4$ & 4 & - & - \\
\hline & & & $<14$ & 29 & $<1.4$ & $<1.4$ & $<4$ & 8 & - & - \\
\hline & & & $<14$ & 18 & $<1.4$ & $<1.4$ & $<4$ & 5 & - & - \\
\hline & & & $<14$ & $<14$ & $<1.4$ & $<1.4$ & $<4$ & $<4$ & - & - \\
\hline & & & $<14$ & $<14$ & $<1.4$ & $<1.4$ & $<4$ & $<4$ & - & - \\
\hline & & & $<14$ & $<14$ & $<1.4$ & $<1.4$ & $<4$ & $<4$ & - & - \\
\hline \multirow[t]{7}{*}{ B } & \multirow[t]{7}{*}{2} & Sep. 4 & $<14$ & $<14$ & $<1.4$ & $<1.4$ & $<4$ & $<4$ & - & - \\
\hline & & $\sim 5$ & $<14$ & $<14$ & $<1.4$ & $<1.4$ & $<4$ & $<4$ & - & - \\
\hline & & 1989 & $<14$ & 140 & $<1.4$ & 2.9 & $<4$ & 40 & - & 98 \\
\hline & & & $<14$ & 50 & $<1.4$ & $<1.4$ & $<4$ & 14 & - & - \\
\hline & & & $<14$ & 32 & $<1.4$ & $<1.4$ & $<4$ & 9 & - & - \\
\hline & & & $<14$ & 94 & $<1.4$ & 4.0 & $<4$ & 27 & - & 96 \\
\hline & & & $<14$ & $<14$ & $<1.4$ & $<1.4$ & $<4$ & $<4$ & - & - \\
\hline \multirow[t]{8}{*}{ Background $^{d)}$} & & Aug. 2 & $<14$ & $<14$ & $<1.4$ & $<1.4$ & $<4$ & $<4$ & - & - \\
\hline & & -3 & $<14$ & $<14$ & $<1.4$ & $<1.4$ & $<4$ & $<4$ & - & - \\
\hline & & 1989 & $<14$ & $<14$ & $<1.4$ & $<1.4$ & $<4$ & $<4$ & - & - \\
\hline & & & $<14$ & $<14$ & $<1.4$ & $<1.4$ & $<4$ & $<4$ & - & - \\
\hline & & & $<14$ & $<14$ & $<1.4$ & $<1.4$ & $<4$ & $<4$ & - & - \\
\hline & & & $<14$ & $<14$ & $<1.4$ & $<1.4$ & $<4$ & $<4$ & - & - \\
\hline & & & $<14$ & $<14$ & $<1.4$ & $<1.4$ & $<4$ & $<4$ & - & - \\
\hline & & & $<14$ & $<14$ & $<1.4$ & $<1.4$ & $<4$ & $<4$ & - & - \\
\hline
\end{tabular}

a) amount of fungicide collected by the front activated carbon fiber paper; b) amount of fungicide collected by the back activated carbon fiber paper; $2 \mathrm{ml}$ of xylene extract was condenced to $0.2 \mathrm{ml} ; \mathrm{c})\left\{\left(A_{\text {front }}-A_{\text {back }}\right) / A_{\text {front }} \times\right.$ 100 ; d) at the Niigata Prefectural Research Laboratory for Health and Environment

\section{文献}

1) 農薬ハンドブック,pp. 183, 191 (1986), (日本植 物防疫協会).

2) J. H. Stamper, H. N. Nigg, W. D. Mahon, A. P. Nielsen, M, D. Royer:J. Agric. Food Chem., 37, 240 (1989).

3) 疋田慶夫, 垂井不二男: 農作業研究, 21 (3), 40 (1986).

４）花井義道, 加藤龍夫, 桘田 博: 横浜国立大学環 境科学研究センター紀要, 12, 47 (1985).

5) P. O. Yeboah, W. W. Kilgore : Bull. Environ. Contam. Toxicol., 32, 629 (1984).
6) 森山 登, 村山 等, 北島永一, 漆山佳雄, 川田邦 明: 衛生化学, 36, 299 (1990).

7）川田邦明, 森山 登, 笠原 貢, 漆山佳雄 : 分析化 学, 39, 425 (1990).

$$
\hat{s}
$$

Simple GC determination of fungicides captan and chlorothalonil in air using activated carbon fiber paper for sampling. Kuniaki Kawata, Noboru Moriyama and Yoshio Urushiyama (Niigata Prefectural Research Laboratory for Health and Environment, 314-1, Sowa, Niigata-shi, Niigata 950-21)

A simple method was developed for the determination 
of captan and chlorothalonil (TPN) in air. Air was taken through two round shaped activated carbon fiber papers with diameter of $47 \mathrm{~mm}$ (Toyobo KF Paper P-175) using an automated sequential air sampler (Tokyo Dylec 10-line Global Sampler GS-10D) at 10 to $201 \mathrm{~min}^{-1}$ for $3 \mathrm{~h}$. Each the sampled paper was extracted ultrasonically with $3 \mathrm{ml}$ of xylene for $10 \mathrm{~min}$ followed by centrifugation at $3000 \mathrm{rpm}$ for $10 \mathrm{~min}$. An aliquot of the supernatant was analyzed by GC equipped with ECD $\left({ }^{63} \mathrm{Ni}\right)$ on a fused-silica capillary column coated with methyl silicone $\left(d_{\mathrm{f}}=2.65 \mu \mathrm{m}, 0.53 \mathrm{~mm}\right.$ i.d. $\times 10$ $\mathrm{m})$. The collection efficiencies and recoveries of captan and TPN were quantitative; the minimum detectable concentrations were $4 \mathrm{ng} \mathrm{m}^{-3}$ for captan and TPN. The fungicides were stable on the paper for a week at $-20^{\circ} \mathrm{C}$. This method was applied to determine captan and TPN in air near golf courses.

(Received May 7, 1990)

\section{Keyword phrases}

fungicides in air; GC; captan; chlorothalonil; activated carbon fiber paper for air sampling. 